\title{
Remote Sensing Calibration of Casey Lake and Silver Lake
}

\author{
Krista Ellyson and Mark D. Ecker \\ Mathematics Department \\ University of Northern lowa \\ Cedar Falls, IA 50614-0506 USA
}

Received: April 27, $2005 \quad$ Accepted: May 9, 2005

\begin{abstract}
This project examines two lowa lakes to explore the feasibility of using remote sensing technologies for assessing water quality in lieu of actual ground samples. We demonstrate that a principal component analysis of the more than 20,000 remote sensed pixels can be used in a regression analysis to accurately predict total phosphorus levels in Casey Lake on three distinct times in the summer of 2004.
\end{abstract}

\section{INTRODUCTION}

The goal of this analysis is to calibrate remote sensing data with ground samples in two local lowa Lakes, Silver Lake in Delhi, lowa and Casey Lake in Tama County, lowa. We examine water quality variables including surface temperature, $\mathrm{pH}$, turbidity, secchi, chlorophyll a, and total phosphorus collected on three occasions during 2004 (June 3, July 8 and July 31) from the two lakes. Remote sensing data taken from aircraft were correspondingly collected for each lake and each of the three times. Variables such as chlorophyll a, turbidity and surface water temperature are traditionally measured from satellite data. However, most of these studies have explored remote sensing applications to large bodies of water such as Lake Michigan [1]. We will address whether the remote sensing variables can be used in lieu of the much more time and labor extensive procedure of collecting ground samples.

We first reduce the number of bands of reflectivity (remote sensed) data from thirty down to a more manageable set without losing much information. We will use tens of thousands of pixels of reflectivity data from each lake at each of the three dates (each pixel having 30 bands) in a principal component analysis. Then the three to five principal components obtained for the pixel most closely aligned with each ground-sampled location will be used in a regression analysis (using the principal components determined by an analysis of the thousands of pixels from the entire lake) with the observed water quality variables, one at a time, as the dependent variable.

\section{REDUCING THE NUMBER OF REMOTE SENSING REFLECTIVITY BANDS}

The two lakes being examined are Casey Lake in Tama County, lowa and Silver Lake in Delhi, lowa. Figures of each lake were constructed from the 22,522 and 25,708 respective remote sensed pixels (see Figure 1 and Figure 2) that were gathered in June 2004. Similar pixel counts were observed for early July and late July of 2004.

In reviewing the spectral bandwidth summary statistics for June 2004, there were 22,522 pixels obtained with 30 bands each in Casey Lake. The lowest levels for each band (B) ranged from 274 to 1,344 and the highest levels recorded for each band ranged from 1,260 to 2,727 . There were 25,708 pixels remote sensed with 30 bands each in Silver Lake. The lowest levels for each band ranged from 638 to 1,664 and the 
highest levels recorded for each band ranged from 1,713 to 5,246 .

Our first objective is to examine the reflectivity data for correlations to reduce the number of bands with minimal loss of information. Thirty separate regression analyses were performed on Casey and Silver lakes using each of the 30 bands as the dependent variable and the remaining 29 as independent. A table was then made (not shown) showing whether or not each band was a significant predictor of the dependent variable. There was an interesting trend in the $R$ squared values. For Casey, the models with B1, B2, and B3 separately as dependent variables explain less than $80 \%$ of the variability using the remaining bands as covariates. For example B1 as the dependent variable would have B2 through B30 as covariates. Specifically, the R squared values for B1, B2 and B3 respectively are $0.5542,0.7517$, and 0.7796 . The rest of the bands as dependent variables explain more than $80 \%$ of the variability. The results are similar with Silver Lake, except that B1 is the only variable that, when it is dependent, it explains less than $80 \%$ or precisely $67.31 \%$ of the variability.

We next looked at the five most significant bands when we examined each of the 30 bands as the dependent variable and the rest as independent as before. It also indicates the five bands in which each of the independent bands is most closely related. In comparing the B1 to B30 levels in Casey and Silver Lakes, it is apparent that the bands are more highly correlated with other bands that are within five. For example in Silver Lake, the highest correlations involving B3 are bands B2, B4, B5, B6, and B7. There are a few correlations that do not follow this pattern in Silver Lake, which may be due to floating objects in the water or incorrect readings, etc., but for the most part each band is very closely related to the bands nearest to them.

Table 1 and Table 2 show a summarized version of the regression and correlation analyses. They show the maximum correlation between each of the individual bands, when each band is dependent. They also show the maximum correlation along with the band that corresponds the closest, as well as the total $\mathrm{R}$ squared value. These tables visually

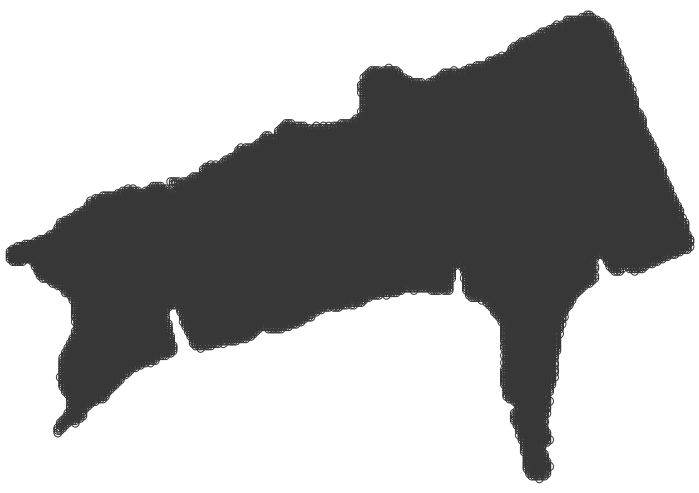

Figure 1. 22,522 reflectivity pixels in Casey Lake.

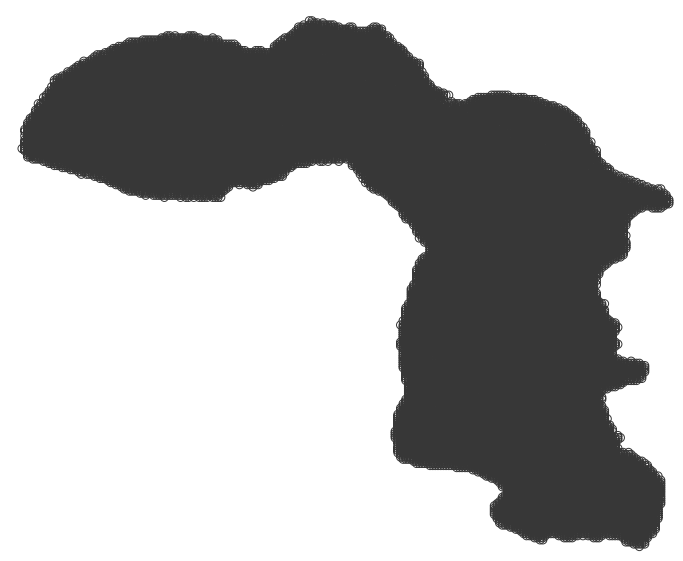

Figure 2. 25,708 pixels in Silver Lake.

show that the highest correlations between the bands are with the bands that are the closest to the variable of interest. For example with Casey Lake in Table 1, B2 is the closest related variable to $\mathrm{B} 1$ with a correlation of 0.692 , and B5 is the closest related variable to $\mathrm{B} 4$ and $\mathrm{B} 6$ with correlations of 0.883 and 0.886 , respectively. There are a few results that do not comply with the pattern of the rest, for example B10 is the closest related variable to B2, but twenty-five out of the thirty follow this pattern. The $R$ squared values also tend to increase with the band number.

Silver Lake also follows a similar pattern of the higher $R$ squared values associated higher band numbers. For example with Silver Lake in Table 2, B2 is the closest related variable to $B 1$ and $B 3$ is the closest related variable to $\mathrm{B} 2$. There are a few more bands with Silver Lake that do 


\begin{tabular}{|l|ll|l|}
\hline \multicolumn{3}{|c|}{ Casey Lake } \\
\hline Band & Max Corr (Variable) & $R$ squared \\
\hline B1 & 0.692 & (B2) & 0.5542 \\
\hline B2 & 0.799 & (B10) & 0.7517 \\
\hline B3 & 0.814 & (B9) & 0.7796 \\
\hline B4 & 0.883 & (B5) & 0.8500 \\
\hline B5 & 0.886 & (B6) & 0.8606 \\
\hline B6 & 0.886 & (B5) & 0.8552 \\
\hline B7 & 0.891 & (B8) & 0.9018 \\
\hline B8 & 0.929 & (B9) & 0.9209 \\
\hline B9 & 0.932 & (B10) & 0.9225 \\
\hline B10 & 0.933 & (B11) & 0.9274 \\
\hline B11 & 0.942 & (B12) & 0.9292 \\
\hline B12 & 0.946 & (B13) & 0.9361 \\
\hline B13 & 0.946 & (B12) & 0.9350 \\
\hline B14 & 0.938 & (B13) & 0.9399 \\
\hline B15 & 0.918 & (B14) & 0.9054 \\
\hline B16 & 0.895 & (B17) & 0.9143 \\
\hline B17 & 0.955 & (B18) & 0.9447 \\
\hline B18 & 0.968 & (B19) & 0.9606 \\
\hline B19 & 0.972 & (B20) & 0.9697 \\
\hline B20 & 0.972 & (B19) & 0.9666 \\
\hline B21 & 0.978 & (B22) & 0.9749 \\
\hline B22 & 0.978 & (B21 \& B23) & 0.9782 \\
\hline B23 & 0.991 & (B25) & 0.9878 \\
\hline B24 & 0.985 & (B23) & 0.9789 \\
\hline B25 & 0.991 & (B23) & 0.9878 \\
\hline B26 & 0.986 & (B23 \& B25) & 0.9855 \\
\hline B27 & 0.986 & (B26) & 0.9822 \\
\hline B28 & 0.984 & (B26 \& B27) & 0.9811 \\
\hline B29 & 0.983 & (B26 \& B28) & 0.9786 \\
\hline B30 & 0.979 & (B26) & 0.9702 \\
\hline & & & \\
\hline
\end{tabular}

Table 1. Casey Lake bands, maximum correlations, and $\mathrm{R}$ squared values.

not comply with the pattern of the rest, but twenty-two out of the thirty follow this pattern. This could be because of the problem mentioned earlier about the possibility of floating objects in the water or incorrect readings. The $\mathrm{R}$ squared values tend to increase with the band number for Silver Lake as well.

A Principal Component Analysis (PCA) was conducted on the spectral bandwidth data for both Silver and Casey
Lakes at each of the three times with our objective being to reduce the number of bands from thirty to between two and five with only a minimal loss of information. The results of the PCA for Silver show that the first two principal components explain $90.3 \%$ of the total variability and the first three account for $95.1 \%$. The first principal component, which explains $73.1 \%$ of the total variability, is a weighted average of all thirty bands, due to the positive correlations amongst all variables. The first two

\begin{tabular}{|l|ll|l|}
\hline \multicolumn{3}{|c|}{ Silver Lake } \\
\hline Band & Max & Corr (Variable) & $R$ squared \\
\hline B1 & 0.722 & (B2) & 0.6731 \\
\hline B2 & 0.907 & (B3) & 0.8934 \\
\hline B3 & 0.923 & (B4) & 0.9221 \\
\hline B4 & 0.985 & (B5) & 0.9813 \\
\hline B5 & 0.985 & (B4) & 0.9822 \\
\hline B6 & 0.979 & (B5) & 0.9796 \\
\hline B7 & 0.963 & (B8) & 0.9769 \\
\hline B8 & 0.977 & (B9) & 0.9785 \\
\hline B9 & 0.977 & (B8) & 0.9764 \\
\hline B10 & 0.976 & (B9) & 0.9745 \\
\hline B11 & 0.982 & (B12) & 0.9801 \\
\hline B12 & 0.982 & (B11) & 0.9814 \\
\hline B13 & 0.975 & (B8) & 0.9818 \\
\hline B14 & 0.968 & (B10 \& B13) & 0.9681 \\
\hline B15 & 0.958 & (B12) & 0.9498 \\
\hline B16 & 0.957 & (B17) & 0.9821 \\
\hline B17 & 0.975 & (B18) & 0.9879 \\
\hline B18 & 0.975 & (B17) & 0.9893 \\
\hline B19 & 0.973 & (B18) & 0.9868 \\
\hline B20 & 0.851 & (B22) & 0.9724 \\
\hline B21 & 0.955 & (B19) & 0.9804 \\
\hline B22 & .0953 & (B21) & 0.9804 \\
\hline B23 & 0.990 & (B25) & 0.9874 \\
\hline B24 & 0.884 & (B25) & 0.9801 \\
\hline B25 & 0.985 & (B23) & 0.9890 \\
\hline B26 & 0.985 & (B23) & 0.9850 \\
\hline B27 & 0.969 & (B26) & 0.9782 \\
\hline B28 & 0.981 & (B25) & 0.9787 \\
\hline B29 & 0.971 & (B28) & 0.9779 \\
\hline B30 & 0.968 & (B29) & 0.9717 \\
\hline
\end{tabular}

Table 2. Silver Lake bands, maximum correlations, and $\mathrm{R}$ squared values. 
principal components explain $94.2 \%$ of the total variability in the thirty bands from Casey Lake. The first principal component, which explains $80.5 \%$ for the total variability, is a weighted average of only bands 17 through 30 . The first 16 bands are not very useful in examining the variability amongst the bands. Thus, the thirty bands from either lake can best be reduced to two or three principal components without much loss of explanatory power.

\section{CORROBORATING GROUND DATA}

The results of the principal component analyses on the reflectivity data from Casey Lake and Silver Lake were investigated to determine how accurate remote sensing data can predict actually sampled water quality data. The water quality variables: Temperature, Secchi (a measure of water clarity), Chlorophyll a, Turbidity, $\mathrm{pH}$ and Total Phosphorus were collected at as many as 20 sites in Silver Lake (see Figure 3 ) and as many as 21 sites in Casey Lake (see Figure 4) for dates in June, early July and late July. Remote sensed data were collected for each lake at each corresponding time. The remote sensed pixels most closely associated with the actual sample locations (as many as 20 in Silver and 21 in Casey) were determined and the first three principal components, obtained from the principal component analysis using the pixels from the entire lake $(22,522$ in June), were separately regressed on each water quality variable (three independent variables and as many as 21 observations or sites). With such relatively small sample sizes, we needed to reduce the number of variables (bands) from thirty to a much smaller number (three) of principal components

Table 3 illustrates the regression results for June 2004 where $P \quad(N)$ represents a positive (negative) parameter estimate and its corresponding significance level is given by the number of asterisks. Ground samples during early July 2004 and late July 2004 were also collected and analyzed in each lake. The first principal component in the June 2004 Silver Lake data explains Temperature, $\mathrm{pH}$ and Chlorophyll well, while the first two explain Turbidity. In Casey Lake, the first principal

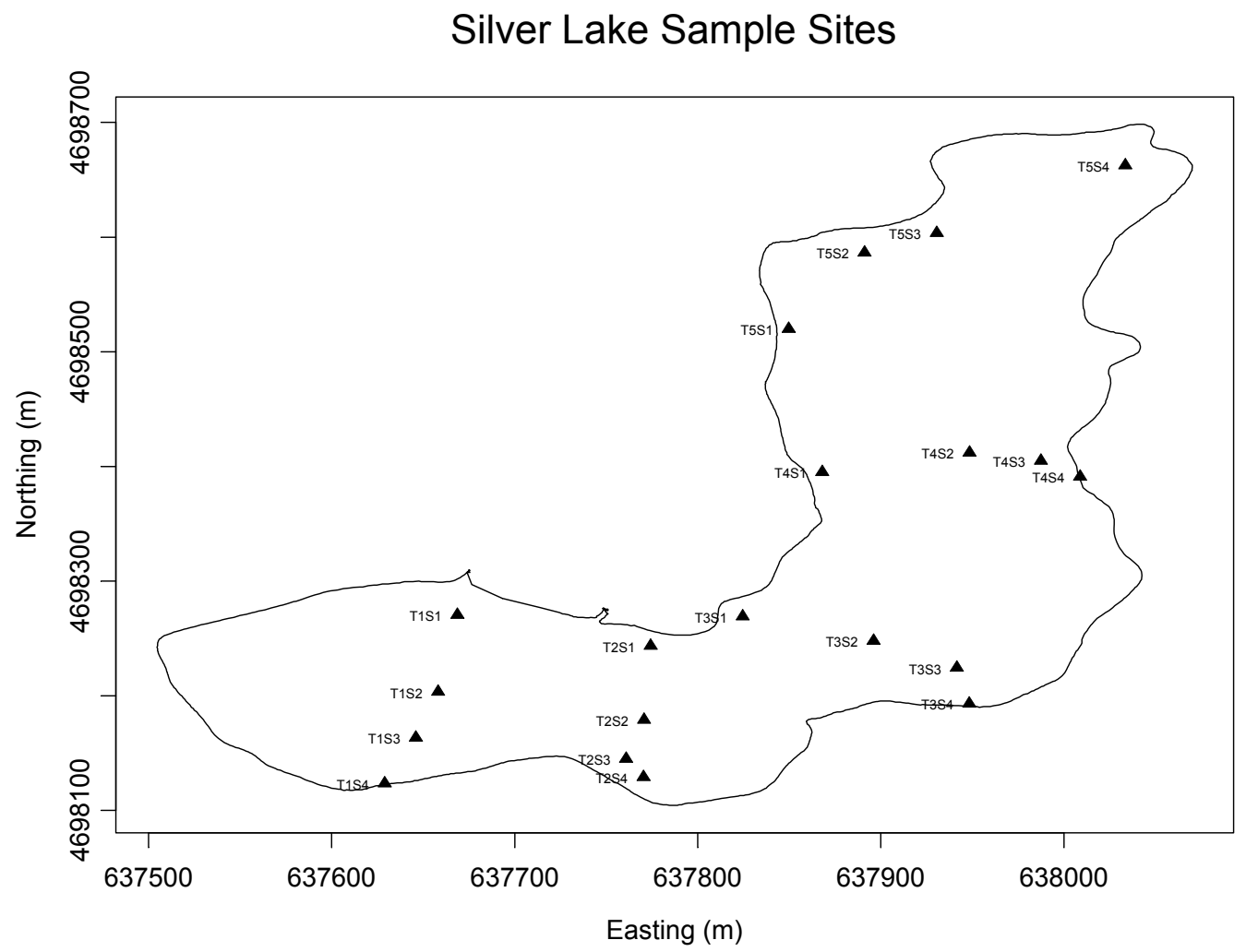

Figure 3. Sampled locations in Silver Lake. 


\section{Casey Lake Sample Sites}

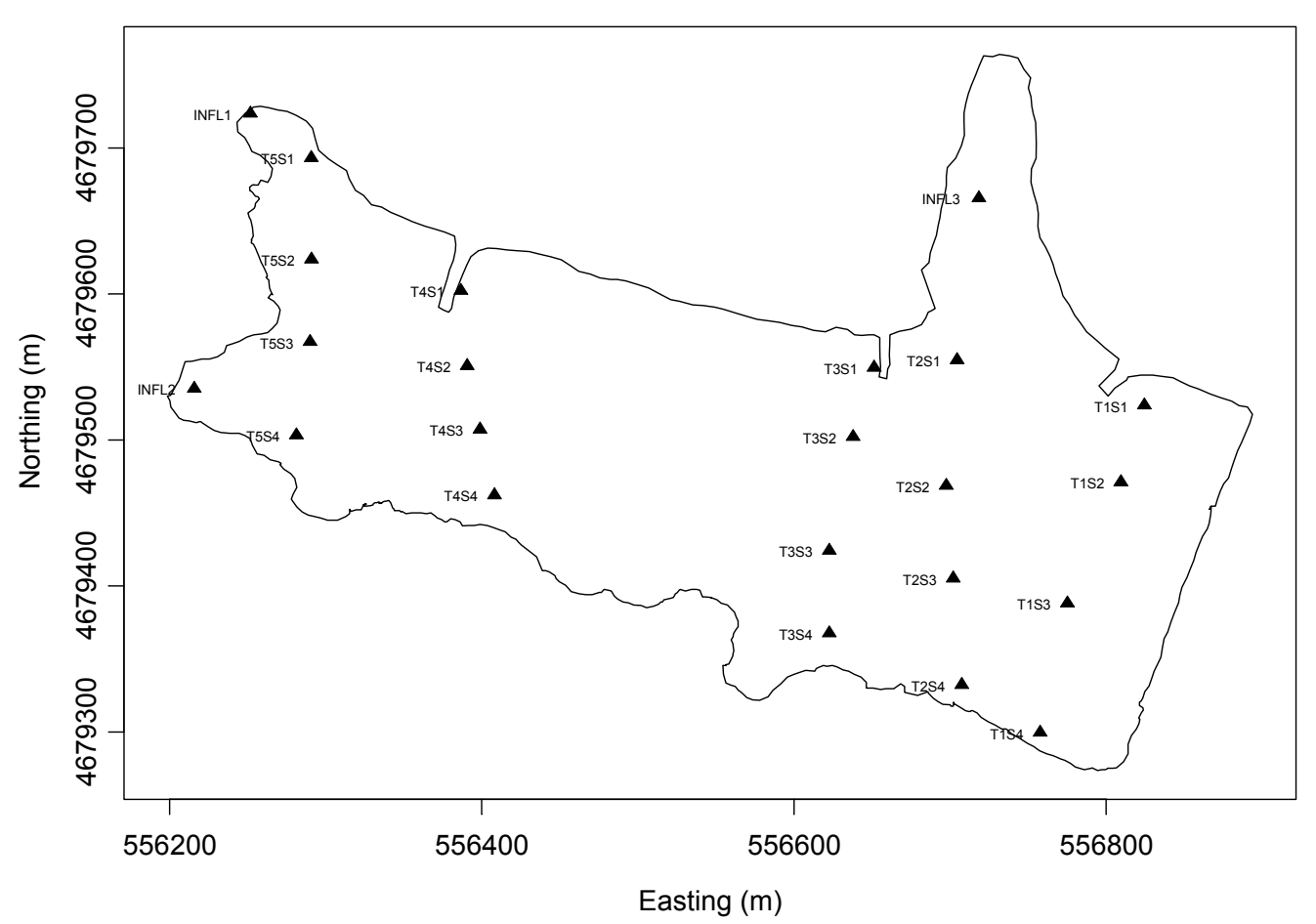

Figure 4. Sampled locations in Casey Lake.

component only explains Temperature. All three principal components are significant in the June 2004 Casey Lake data in explaining the total phosphorus. Note that no principal components explain total phosphorus in Silver Lake. This observation may be due to the quite different water chemistry found in each lake. Silver Lake is more polluted with much higher levels of phosphorus than Casey Lake (see [2, 3]).
We next examine the PCA results for the water quality variable total phosphorus in Casey Lake during the June, early July and late July collection times in Table 4. The first three principal components explain the amount of phosphorus in the lake well. A better illustration of the quality of the remote sensed results for total phosphorus in Casey Lake would compare the actual sampled

\begin{tabular}{|l|l|l|l||l|l|l|}
\hline & \multicolumn{3}{|c||}{ SILVER } & \multicolumn{3}{c|}{ CASEY } \\
\hline & $\mathrm{PC1}$ & $\mathrm{PC2}$ & $\mathrm{PC} 3$ & $\mathrm{PC} 1$ & $\mathrm{PC2}$ & $\mathrm{PC} 3$ \\
\hline Temperature & $\mathrm{P}^{* * * *}$ & & & $\mathrm{P} * *$ & & \\
\hline $\mathrm{pH}$ & $\mathrm{P}^{*}$ & & & & $\mathrm{~N}^{* * *}$ & \\
\hline Turbidity & $\mathrm{P}^{* * *}$ & $\mathrm{~N}^{*}$ & & & & \\
\hline Secchi & & & & & $\mathrm{N}^{* *}$ & \\
\hline Chlorophyll a & $\mathrm{N}^{* * *}$ & & & & & \\
\hline Total Phosphorus & & & & $\mathrm{P}^{* *}$ & $\mathrm{P}^{*}$ & $\mathrm{~N}^{* *}$ \\
\hline
\end{tabular}

Table 3. Principal component analysis/regression results for June 2004. * Indicates significance at the alpha $=0.15$ level; ${ }^{* *}$ Indicates significance at the alpha $=0.10$ level; ${ }^{* * *}$ Indicates significance at the alpha $=0.05$ level; and ${ }^{* * * *}$ Indicates significance at the alpha $=0.01$ level. 
values to the remote sensed fitted or predicted values (see Table 5). For example, the actual value of total phosphorus in Casey Lake in June 2004 at Transect 1, Site 1 (T1S1) was 73.9. The predicted value obtained from regressing the first three principal components, obtained via the principal component analysis of the 25,522 remote sensed pixels from Casey Lake in June, on total phosphorus is 80.6. Similarly, we observed 42.1 in early July and 151.8 in late July, whereas, the corresponding predicted values from the regression model are 47.4 and 120.9, respectively.

Finally, we use the regression results coupled with the principal component analysis to estimate the total phosphorus for each of the 22,522 pixels in Casey Lake. Figure 5 displays the 215 sites in Casey Lake where the total phosphorus levels are predicted to be higher than 390 . The highest

\begin{tabular}{|l|l|l|l|}
\hline & \multicolumn{1}{|c|}{$\mathrm{PC} 1$} & \multicolumn{1}{|c|}{$\mathrm{PC2}$} & \multicolumn{1}{c|}{$\mathrm{PC3}$} \\
\hline June & $\mathrm{P}^{* *}$ & $\mathrm{P}^{*}$ & $\mathrm{~N}^{* *}$ \\
\hline Early July & $\mathrm{P}^{* * *}$ & $\mathrm{P}^{* * *}$ & $\mathrm{P}^{*}$ \\
\hline Late July & $\mathrm{P}^{* * *}$ & & $\mathrm{~N}^{* * *}$ \\
\hline
\end{tabular}

Table 4. Significance of the independent variables (principal components) in the regression analysis of Total Phosphorus in Casey Lake for 2004 (for the notation indicating significance at the alpha level, see Table 3).

one percent of the total phosphorus predicted values tend to be located at the inflows to Casey Lake and along the shore, particular the southern portion. Future work will include actual sampling at the lake perimeter to determine if these results are accurate or a direct result of different reflectivity properties along the shore (possibly due to the shallow water depth).

\begin{tabular}{|l|l|l|l|l|l|l|}
\hline $\begin{array}{l}\text { Casey } \\
\text { Lake } \\
\text { Sites }\end{array}$ & $\begin{array}{l}\text { June } \\
\text { Photal } \\
\text { Phosphorus }\end{array}$ & $\begin{array}{l}\text { June } \\
\text { Values }\end{array}$ & $\begin{array}{l}\text { Early July } \\
\text { Total } \\
\text { Phosphorus }\end{array}$ & $\begin{array}{l}\text { Early July } \\
\text { Predicted } \\
\text { Values }\end{array}$ & $\begin{array}{l}\text { Late July } \\
\text { Total } \\
\text { Phosphorus }\end{array}$ & $\begin{array}{l}\text { Late July } \\
\text { Predicted } \\
\text { Values }\end{array}$ \\
\hline T1S1 & 73.9 & 80.62 & 42.1 & 47.38 & 151.8 & 120.09 \\
\hline T1S2 & 80.7 & 76.62 & 47.8 & 46.40 & 126 & 92.27 \\
\hline T1S3 & 84.1 & 78.62 & 44.3 & 41.50 & 100.9 & 82.42 \\
\hline T1S4 & 84.1 & 81.54 & 40.4 & 45.50 & 138.7 & 103.91 \\
\hline T2S1 & 70.6 & 71.71 & 43.9 & 41.40 & 110.5 & 102.76 \\
\hline T2S2 & 70.6 & 70.12 & 40.4 & 47.38 & 88.0 & 96.70 \\
\hline T2S3 & 77.3 & 72.78 & 43.9 & 46.85 & 81.9 & 90.97 \\
\hline T2S4 & 80.7 & 79.41 & 54.7 & 55.22 & 107.7 & 120.52 \\
\hline T3S1 & 84.1 & 76.23 & 44.3 & 48.30 & 92.1 & 109.71 \\
\hline T3S2 & 63.8 & 72.49 & 45.6 & 46.26 & 101.6 & 102.90 \\
\hline T3S3 & 70.6 & 73.54 & 38.6 & 31.58 & 99.6 & 102.44 \\
\hline T3S4 & 73.9 & 79.22 & 38.6 & 38.39 & 98.2 & 118.08 \\
\hline T4S1 & No Data & No Data & 38.6 & 55.55 & 101.3 & 146.73 \\
\hline T4S2 & No Data & No Data & 40.4 & 40.94 & 125.1 & 139.19 \\
\hline T4S3 & No Data & No Data & 38.6 & 39.21 & 81.2 & 102.18 \\
\hline T4S4 & No Data & No Data & 45.3 & 57.73 & 221.9 & 175.69 \\
\hline T5S1 & No Data & No Data & 57.9 & 49.85 & No Data & No Data \\
\hline T5S2 & No Data & No Data & 49.1 & 45.59 & No Data & No Data \\
\hline T5S3 & No Data & No Data & 45.6 & 48.07 & No Data & No Data \\
\hline T5S4 & No Data & No Data & 63.1 & 65.19 & No Data & No Data \\
\hline Inflow3 & 84.10 & 85.59 & 94.6 & 59.50 & 94.7 & 114.65 \\
\hline
\end{tabular}

Table 5. Actual total phosphorus values together with the modeled phosphorus values from remote sensed data for Casey Lake. 


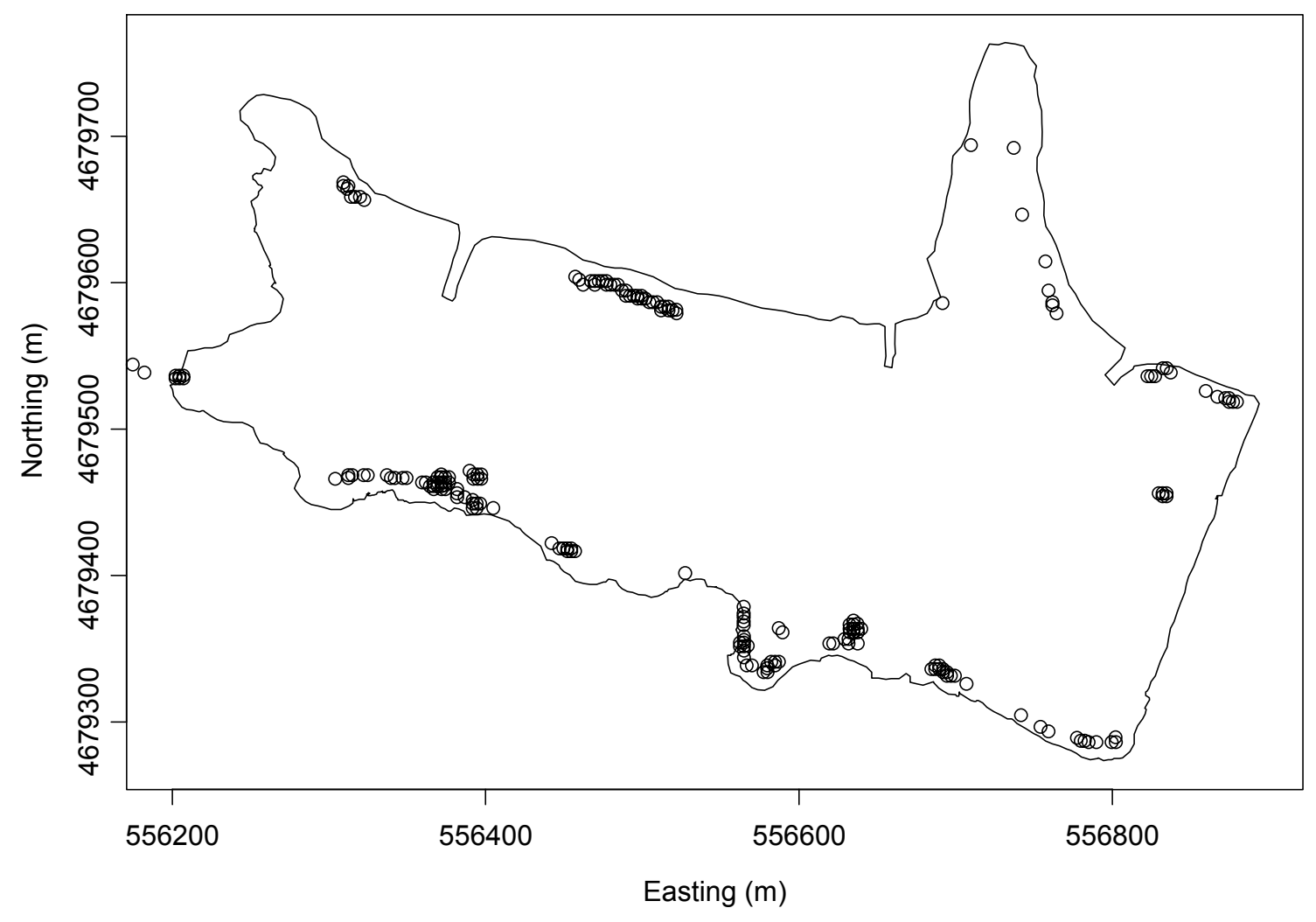

Figure 5. Highest $1 \%$ of Phosphorus predicted levels in Casey Lake.

\section{CONCLUSIONS}

This project calibrated remote sensing data predictions of water quality variables with results actually obtained on the ground through sampling. The results indicate that the total phosphorus level in Casey Lake was fairly well predicted using only remote sensed reflectivity data. Total phosphorus can be predicted for over 22,000 unsampled sites based on satellite data. Given the high costs, in terms of labor and time, of obtaining and subsequently analyzing these water samples, remote sensing may be a plausible and efficient alternative for total phosphorus in Casey Lake.

\section{ACKNOWLEDGEMENTS}

The authors would like to thank Professor Ramanathan Sugumaran and Nathan Green for their assistance in this project.

\section{REFERENCES}

1. Stein, M. "Measuring phytoplankton levels using satellite data for Lake Michigan" [Invited talk, Joint Statistical Meetings, Indianapolis, Indiana, USA, 2000)

2. Carlson, E. and Ecker, M.D. "A Statistical Examination of Water Quality in Two lowa Lakes". American Journal of Undergraduate Research. 1(2). pp 31 - 45 (2002).

3. Oelmann, A. and Ecker, M.D. (2002). "A Statistical Examination of Sediment Phosphorus from Silver Lake and Lake Casey in 2002". Technical Report, Department of Mathematics, University of Northern lowa. Available at www.math.uni.edu/ ecker/research.html.

\section{UNIVERSITY OF NORTHERN IOWA MATHEMATICS}


